\title{
BOOSTER COORDINATES
}

\section{UPDATE}

Booster Technical Note

No. 6

Z. Parsa

January 28, 1986

HIGH ENERGY FACILITIES

Brookhaven National Laboratory

Upton, N.Y. 11973 


\section{ABSTRACT}

THIS NOTE UPDATES THE AGS-BOOSTER COORDINATES, WHICH HAVE BEIN MODIFIED DUE TO AN ARCHITECTUAL RELOCATION OF THE CENTER OF THE BOOSTER. IT DESCRIBES 'THE COORDINATES OF THE AGS BODSTER IN THE BOOSTER CENTERED FRAME OF REFERENCE WITH AXES IN THE NORTH (X) AND EAST ( $Y$ ) DIRECTIONS. TRANSFORMATION FROM THE BOOSTER CENTEREJ FRAME TO THE AGS AND BNL GRIDS ARE DISCUSSED, AND THE COORDINATES OF THE MACHINE WITH REISPECT TO THESE FRAMES ARE GIVEN. 


\section{INTRODUCTION}

This note updates the AGS - Booster coordinates, which have been changed due to an architectual [1] relocation of the center of the Booster.

Previously [2], we generated and described the Booster coordinates in the AGS, BNL and Booster centered frames, using the modified parameters [3] (Circumference $=201.78 \mathrm{~m}$ and Quadrupole length $=0.050375 \mathrm{~m}$ ). These modifications have resulted an architectual change in the center coordinates of the Booster [given in section III] and hence a need to readjust the Boostej: coordinates.

In section II we describe the Booster centered reference frame with axes in the North (X) and East ( $Y$ ) directions, with the unit of length expressed in meters.

In section III, the transformation from the Booster centered reference frame to the AGS and BNL grids are discussed, and the coordinates of the Booster with respect to these frames are tabulated.

Layout of the Booster lattice [4] showing relative position of magnets and the labling convention of the lattice and its superperiods are a.lso included (see Figures 1-3).

\section{BOOSTER CENTERED COORDINATE SYSTEM}

The coordinates of the Booster lattice in the Booster centered coordinate syistem (with East (X) and North (Y) axes where the length is measured in meters) using Tape 5 [5] of program SYNCH, were generated assuming that:

1. The magnets have sharp edges where the field becomes zero.

2. The values Listed in Table I correspond to the coordinates of an on-axis point of the downstream end of that element when viewed in a clockwise direction.

We note that, the effect of the earth's curvature for the Booster is negligable. 
III. TRANSFER OF COORIINATES TO AGS AND BNL GRID

We can use the following transformation from the Booster centered frame of reference to that of AGS and BNL grids asuuming that the axes of the Booster centered coordinate isystem are parallel to those of 1) AGS and 2) BNL grids. Here $X_{B S T}$ and $Y_{B S T}$ are the $x$ and $y$ distances expressed in the Booster coodinate system, with $\mathrm{E}$ and $\mathrm{N}$ a:s the East and North coordinates and $E O$ and NO are the the coordinates of the Booster in the 1) AGS [E(inch), N(inch)] and 2) BNL [E(feet), N(feet)] grids respectively:

1. AGS GRID

$$
\begin{aligned}
& \mathrm{E}(\text { inch })=\underset{\mathrm{AGS}}{\mathrm{EO}}(\text { inch })+\mathrm{X}_{\mathrm{BST}} \text { (inch) } \\
& \mathrm{N}(\text { inch })=\mathrm{NO}_{\mathrm{AGS}}(\text { inch })+\mathrm{Y}_{\mathrm{BST}} \text { (inch) } \\
& \mathrm{EO}(\text { inch })=1,148.88 \\
& \mathrm{AGS} \\
& \mathrm{NO}(\text { inch })=15,459.36
\end{aligned}
$$

2. BNL GRID

$$
\begin{aligned}
& \mathrm{E}(\text { feet })=\underset{\mathrm{BNL}}{\mathrm{EO}}\left(\text { feet) }+\mathrm{X}_{\mathrm{BST}}(\text { feet) }\right. \\
& \mathrm{N}(\text { feet })=\underset{\mathrm{BNL}}{\mathrm{NO}}(\text { feet })+\mathrm{Y}_{\mathrm{BST}}(f e e t) \\
& \mathrm{EO}(f e e t)=98,517.19 \text { feet, and } \\
& \mathrm{BNL} \\
& \mathrm{NO}(\text { feet })=102,438.28 \text { feet. }
\end{aligned}
$$

where the values for $\mathrm{E} O$ and NO were obtained from [1], (using the conversion factor of $2.54 \mathrm{~cm} /$ inch).

Note that the origins of the two systems are different. 
REFERENCES :

1. We received the changes for the Booster center coordinates (due to architectual relocation) from M. schaeffer, January $27,1986$.

2. Booster Coordinates, Booster Tech Note No. 3, Z. Parsa, F. Dell, (January 17, 1986).

3. Booster Parameters, Booster Tech. Note No. 2, Z. Parsa, (January 16, 1986).

4. Booster Lattice, Bcoster Tech. Note No. i, E. Courant and Z. Parsa, (January 15, 1986).

5. Using DUAO: [PARSA1.BOOSTER]SYNBOOST.DAT, a tape 5 [BSTR5, E. Courant] was generated. 


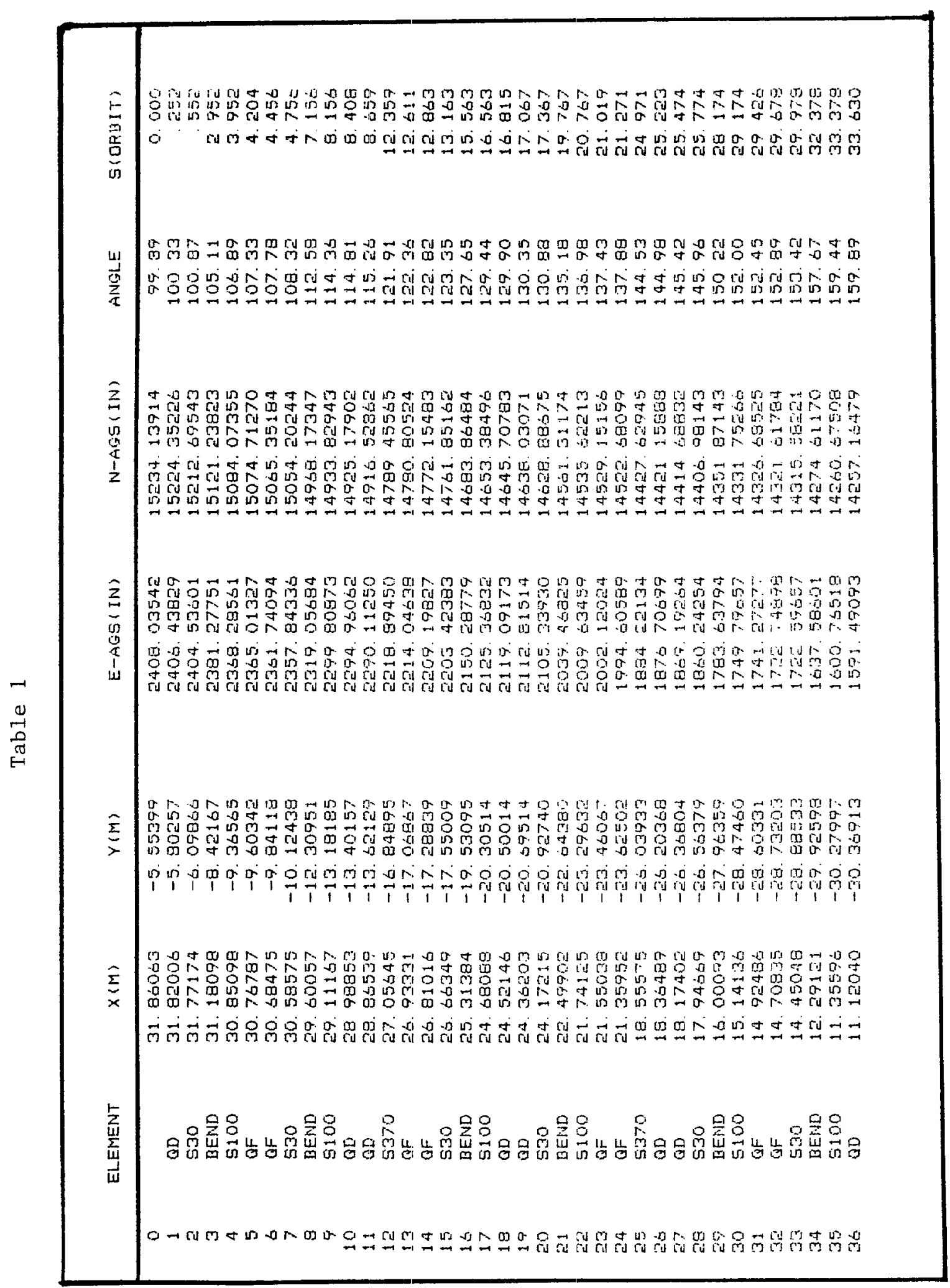




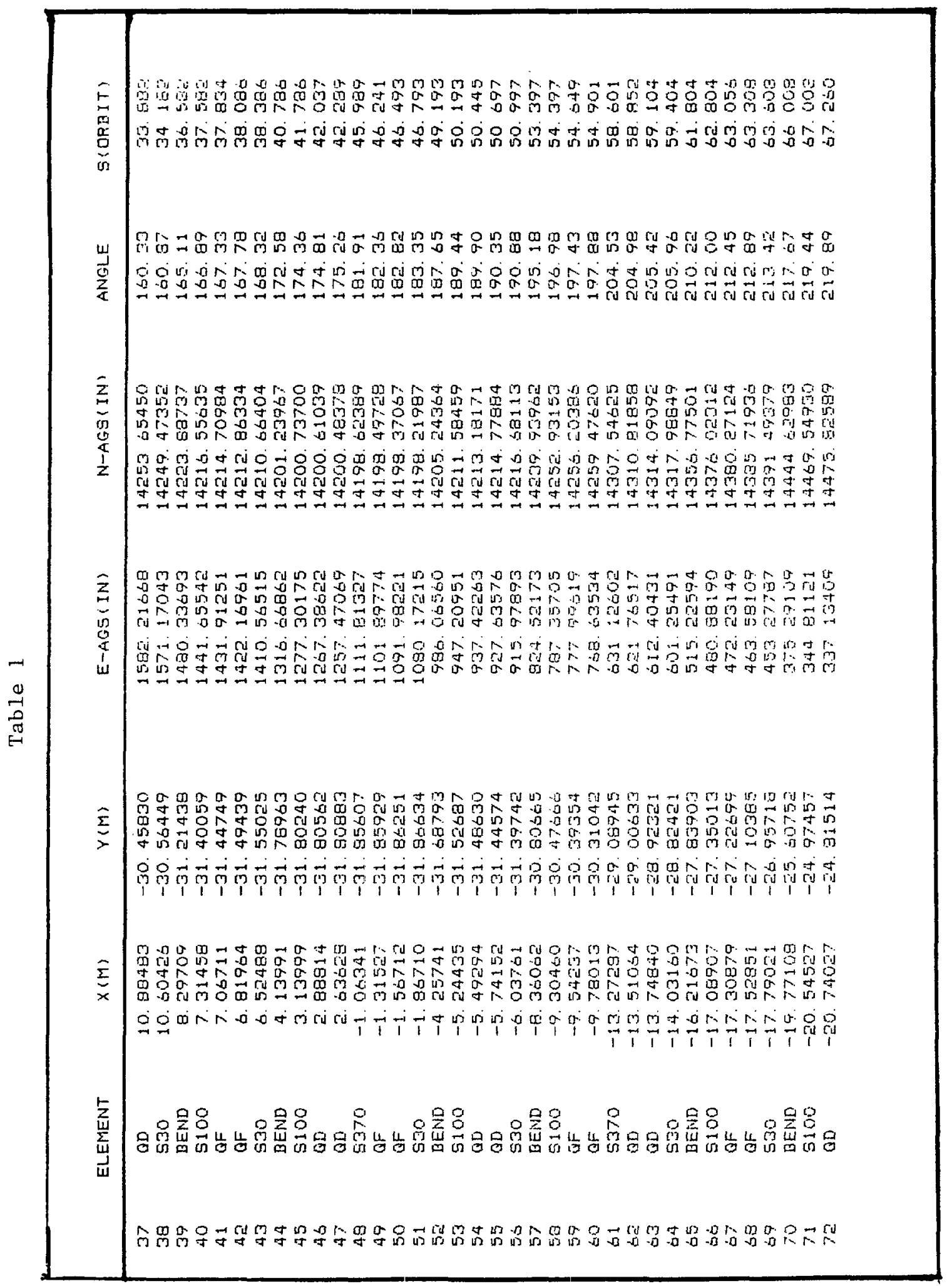




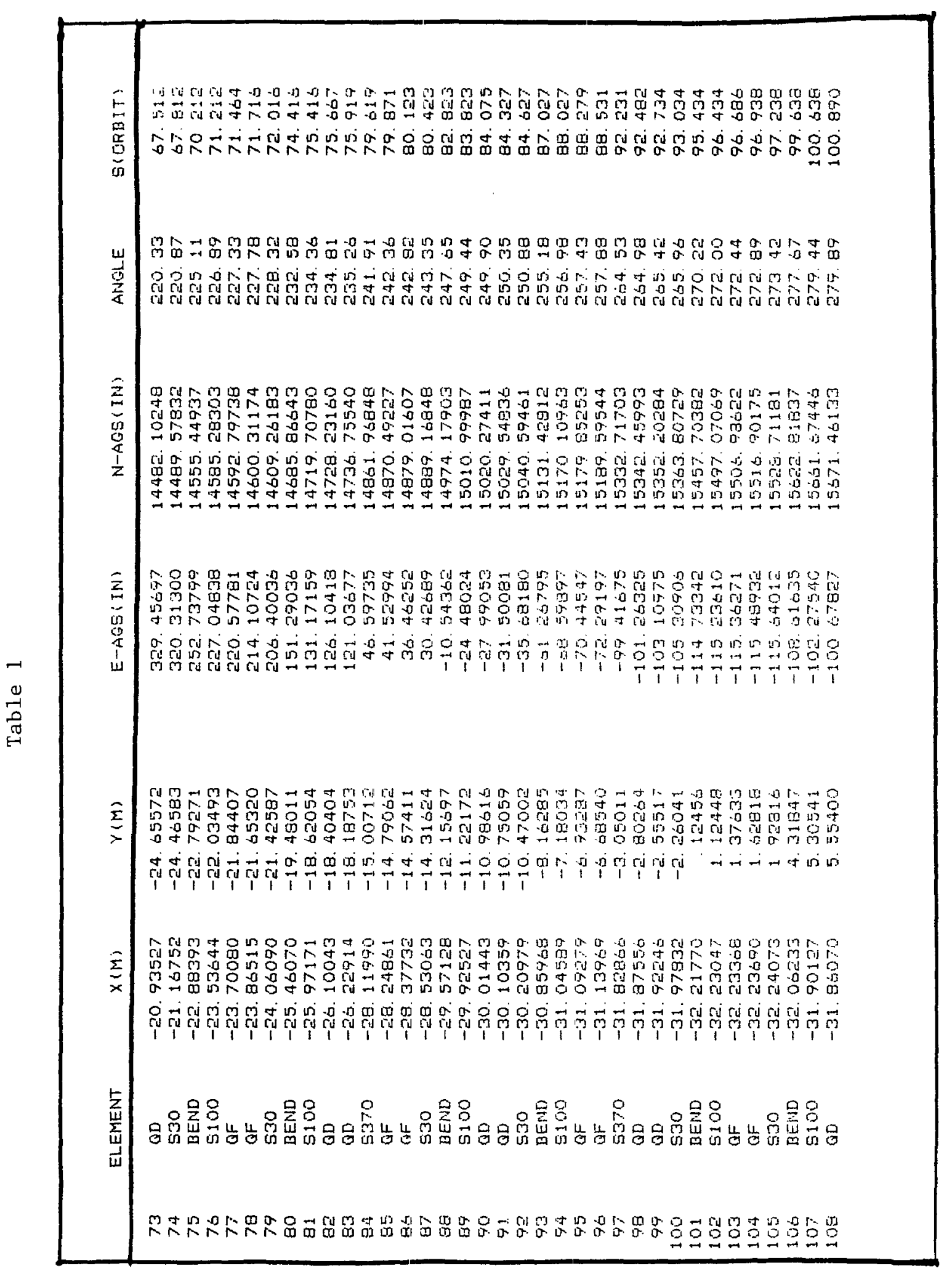




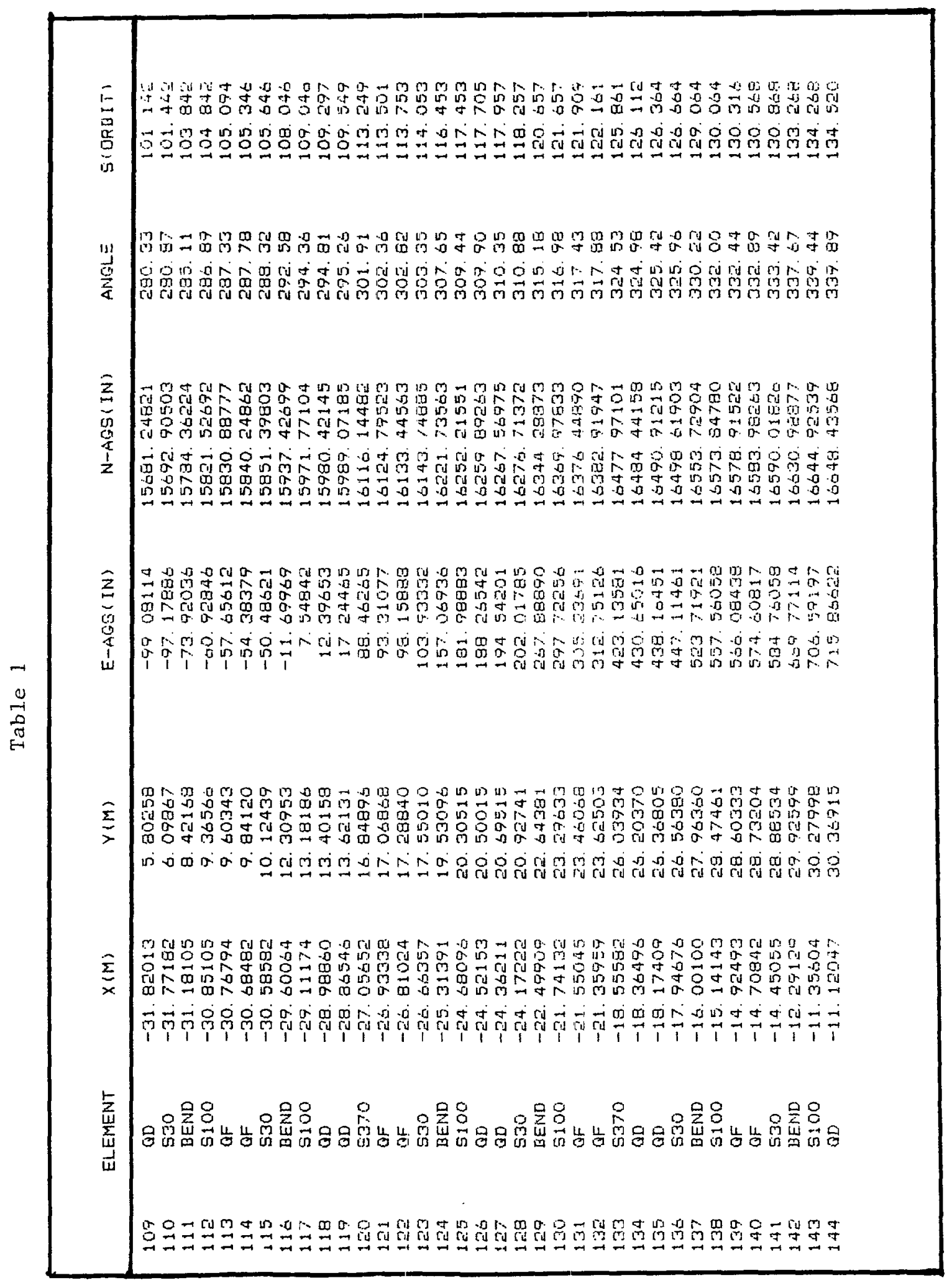




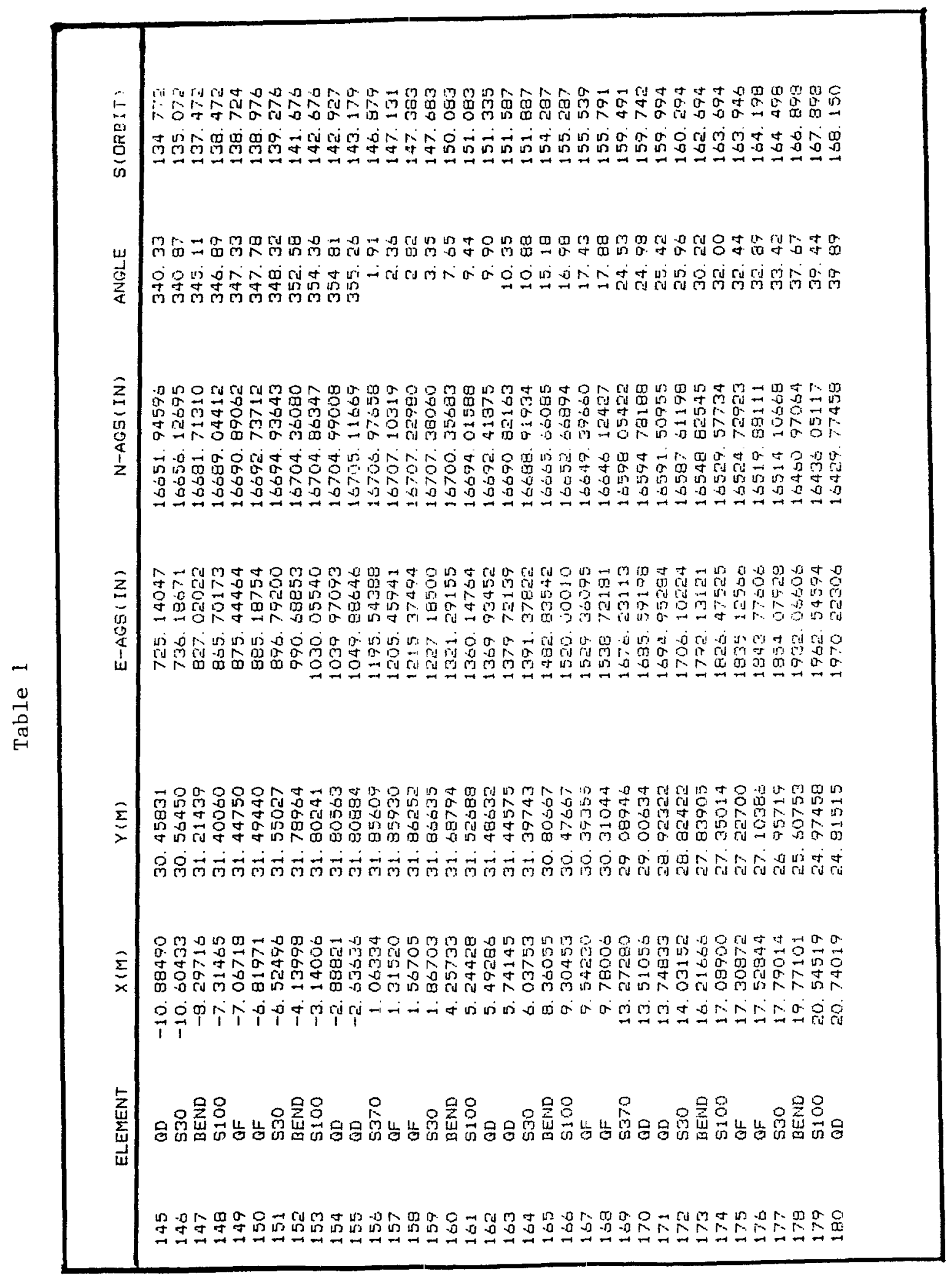


ไู่

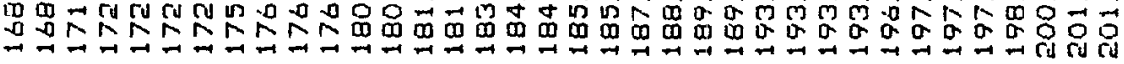

山

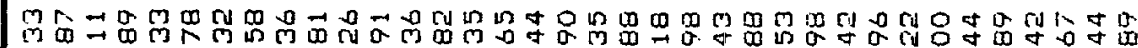
$\frac{5}{4}$

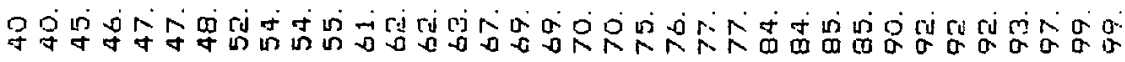

$\sum_{m}$

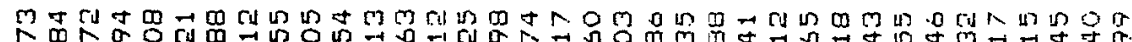

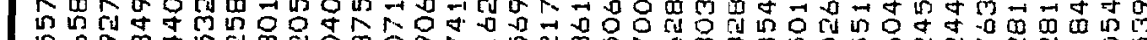

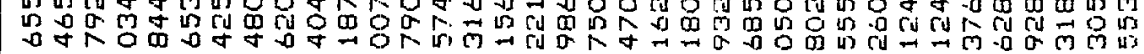

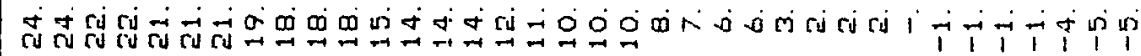

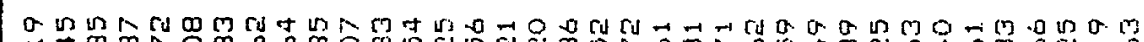

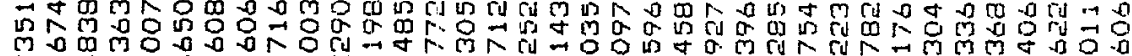
o- 0 un

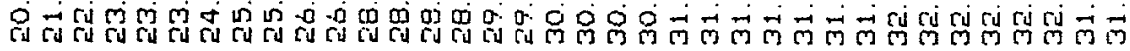

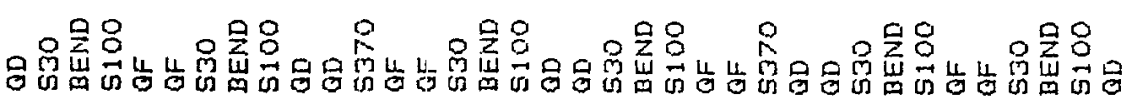

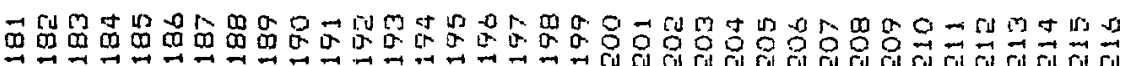


Page 11

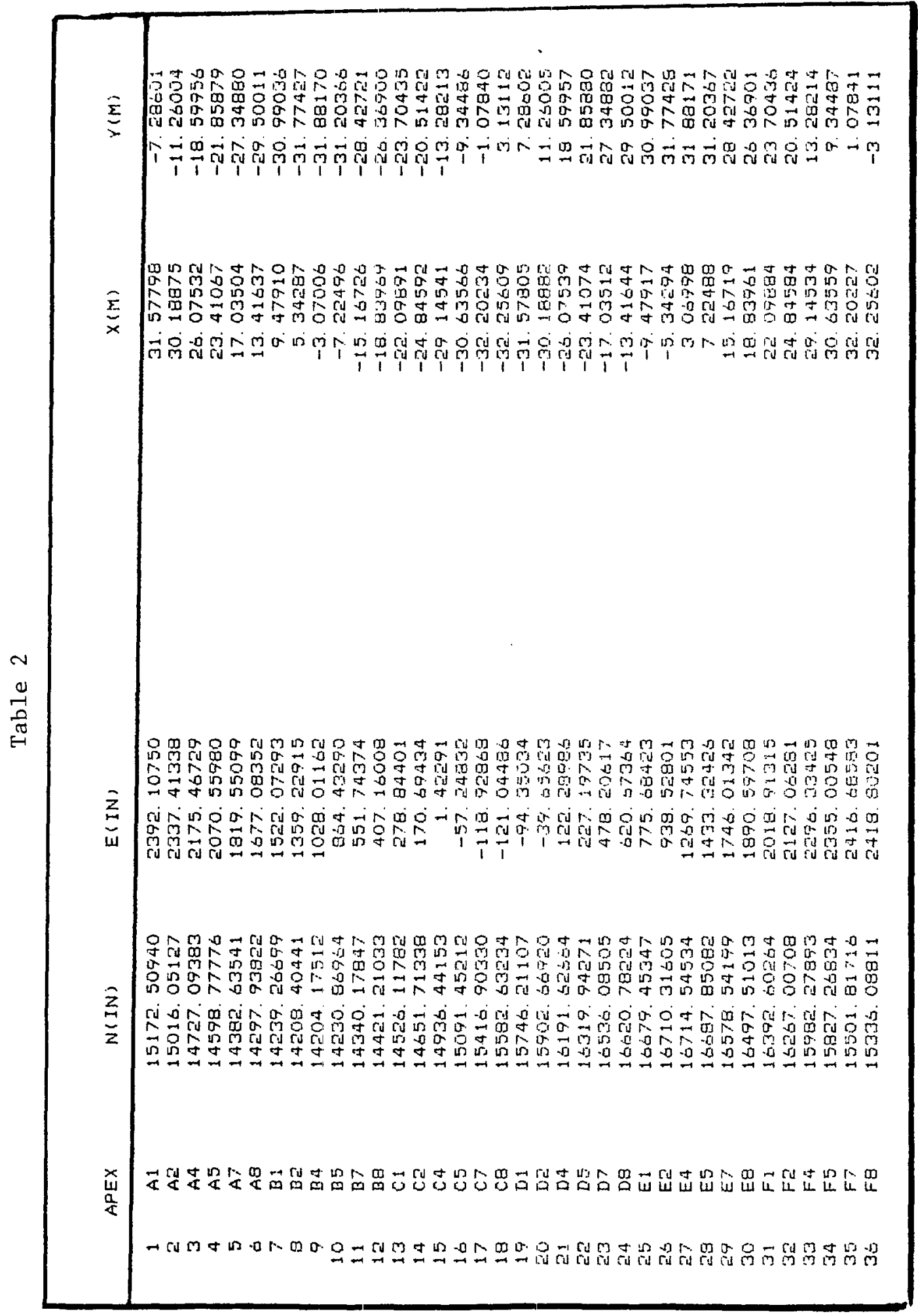




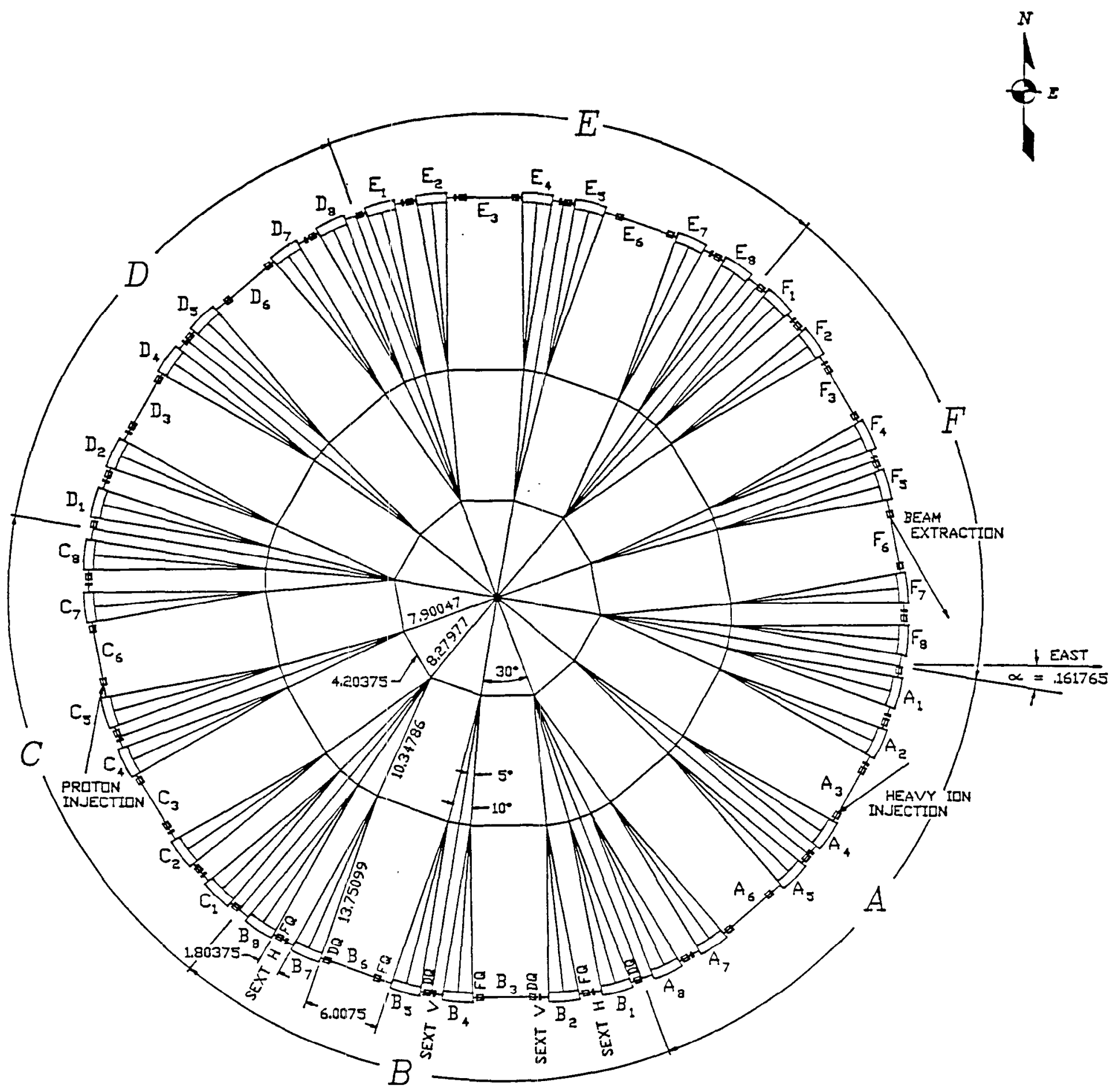

FIG. 1 Gerall Layout: of the AGS Booster 


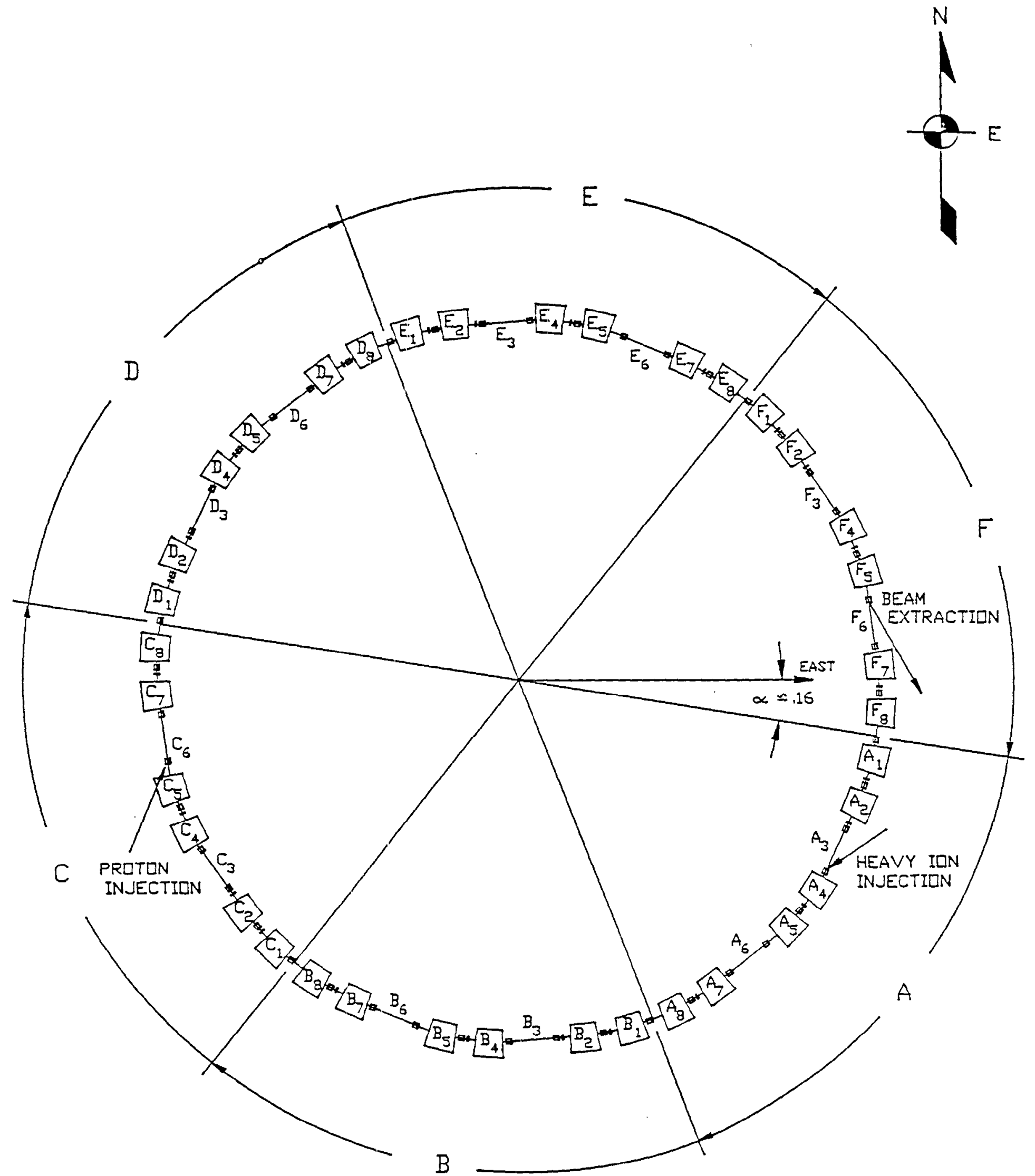

Fig.2 Layout of the AGS Bcoster showing the relative position of magnets (e.g. Dipole Apex locations) and labling convention of the Booster Superperiods. (A to $F$, with the Beam in the Clockwise direction). 


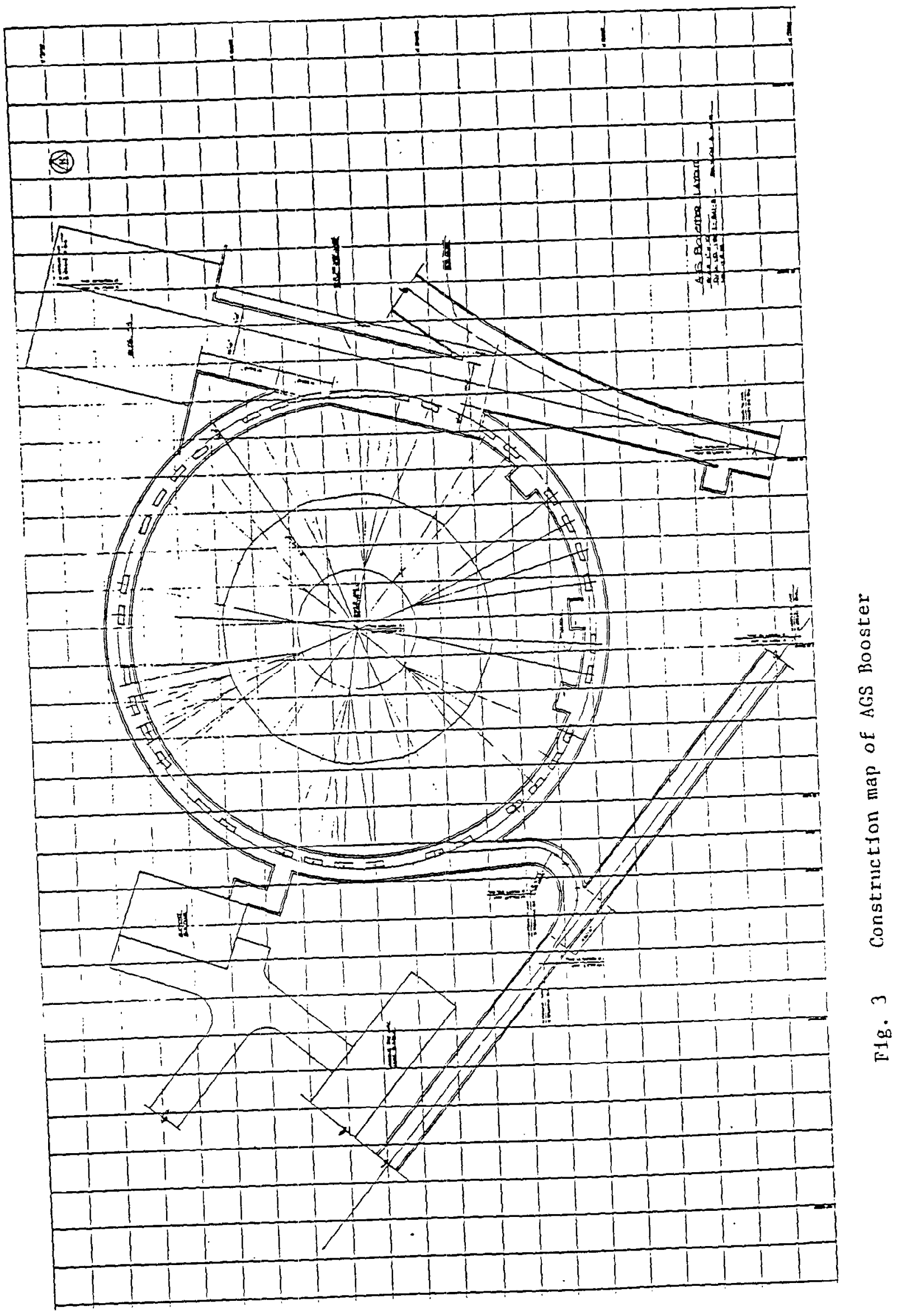

